OPEN ACCESS

Edited by:

Rongwei Chu,

Fudan University, China

Reviewed by:

Russell Kabir,

Anglia Ruskin University,

United Kingdom

Sujita Kumar Kar,

King George's Medical

University, India

${ }^{*}$ Correspondence:

Yurou Zhao

zhaoyr19@mails.jlu.edu.cn

Specialty section:

This article was submitted to

Personality and Social Psychology,

a section of the journal

Frontiers in Psychology

Received: 02 December 2020 Accepted: 08 March 2021

Published: 01 April 2021

Citation:

Jin $X$, Zhao $Y$, Song $W$ and Zhao $T$

(2021) Save for Safe: Effect of

COVID-19 Pandemic on Consumers'

Saving and Spending Behavior in

China. Front. Psychol. 12:636859.

doi: 10.3389/fpsyg.2021.636859

\section{Save for Safe: Effect of COVID-19 Pandemic on Consumers' Saving and Spending Behavior in China}

\author{
Xiaotong Jin ${ }^{1}$, Yurou Zhao ${ }^{1 *}$, Wei Song ${ }^{1}$ and Taiyang Zhao ${ }^{2}$ \\ ${ }^{1}$ Business School, Jilin University, Changchun, China, ${ }^{2}$ School of Philosophy and Sociology, Jilin University, Changchun, \\ China
}

In public health emergencies, people are more willing to save money rather than spending it, which is not conductive to economic development and recovery. Due to the absence of relevant research, the internal logic of this phenomenon is not clear. In the context of the COVID-19 pandemic, this study systematically explored whether and why public health emergencies stimulate consumers' preference for saving (vs. spending). We conducted two online surveys and used methods including stepwise regression analysis and bootstrapping to test the hypotheses. The first survey, with 1,511 participants from China in February 2020, indicates that the severity of emergencies has a significant positive impact on the populations' willingness to save (vs. spend). Risk perception plays a mediating role between the severity of emergencies and consumers' saving (vs. spending) willingness. Materialism plays a moderating role between risk perception and an individual's saving (vs. spending) willingness, individuals who are more materialistic have a lower saving (vs. spending) willingness when they perceive the risks of the pandemic. To verify the duration of the above effects, we conducted a follow-up survey consisted of 466 instances in August 2020. It is noteworthy that the above effects are not significant during the post-pandemic period. Thus, spending behavior in public health emergencies can be motived by reducing risk perception and increasing materialism. These findings can provide a valuable inspiration for public health, crisis management, and economic recovery during public health emergencies.

Keywords: COVID-19, saving and spending, risk perception, materialism, post-pandemic

\section{INTRODUCTION}

Emergencies can include natural disasters, accidental disasters, public health incidents, and social security incidents that occur suddenly, cause or may have the potential to cause serious harm to human life and environment and require emergency response measures. Since emergencies occur suddenly and have continuous impacts, they often cause serious damage to social order, life, public environment, and resources (Behar-Zusman et al., 2020; Wang and Su, 2020), and have a strong and far-reaching impact on the national economy (Muthuraman and Haziazi, 2020). The current COVID-19 pandemic has caused severe damage to the global economy. Therefore, economic recovery has become an important goal for governments globally. It is a known fact that economic recovery (during and after a pandemic) is inseparable from consumer consumption stimulation. However, contrary to this fact, people's consumption behaviors during pandemic usually tend to 
be disorderly and chaotic. One of the most typical behavior during the COVID-19 pandemic is panic buying (Arafat et al., 2020a), which results from individuals' fear of scarcity, losing control, and anxiety exacerbation (Arafat et al., 2020b; Yuen et al., 2020). In this case, individuals cope with threats by purchasing specific products, such as necessities (Jin et al., 2020; Sharma et al., 2020). However, in order to better deal with future uncertainties and risks, individuals' may also reserve resources and increase saving behavior. It is observed that individuals facing a pandemic save more than those who are not. For example, a survey in China showed that more than half of the country's households increased their savings and reduce their spending due to the pandemic; compared to the same period last year (when there was no pandemic) (Survey and Research Center for China Household Finance, 2020), the average savings of the younger generation increased by $34 \%$ (Fidelity International Alipay, 2020). Even Americans who are known for not loving saving money (De Rugy, 2004) show the same behavioral tendency. According to data from the Bureau of Economic Analysis (BEA) in April 2020 (Bureau of Economic Analysis, 2020), the personal savings rate in the United States hit an all-time high, reaching $33 \%$, compared to the $12.7 \%$ that was observed in March 2020. While the savings rate is rising, the Visa report shows that consumer payments (of Americans) are plummeting (Cable News Network, 2020). These phenomena indicate the impact of COVID-19 pandemic on consumers' saving and spending behavior.

In fact, research in the field of economics has put forward the theory of uncertain consumption, which states that individuals will increase their savings and reduce spending under uncertain circumstances (Leland, 1968; Choi et al., 2001; Menegatti, 2001). However, this theory was put forward under ideal economic assumptions. Previous studies have also verified it at the macro level, failing to conduct research for a combination of specific situations and deep levels of individual psychology. Therefore, we raise the following questions: what is the psychological mechanism between the pandemic and an individual's saving and spending behavior? Is the effect long-term or short-term? Does everyone have the same behavior tendency? These issues are not yet clear and need to be resolved urgently. Our study is based on the background of the COVID-19 pandemic and introduces a risk perception theory to explore the above issues. Through the exploration of the above three issues, our study will provide suggestions on how to have a better understanding of consumer psychology and behavior during a pandemic. This analysis aims to provide a sound knowledge of consumerism during an emergency (like a pandemic) and to provide data that can help restore economy in such cases.

\section{THEORETICAL FRAMEWORK}

\section{Saving vs. Spending During the Pandemic}

Saving and spending are not only the key nodes of individual consumption activities but are also important factors affecting economic development and growth. Therefore, saving and spending have been the focus of western economic research for a long time, and a series of classic theoretical frameworks have been formed based on them, such as the life-cycle hypothesis
(Modigliani and Brumberg, 1954) and the precautionary savings hypothesis (Leland, 1968). Although these hypotheses provide theoretical support for economic model research, they are implemented at the macroeconomic level and fail to consider consumer psychology. Previous studies have found that consumers may increase preventive savings for dealing with impacts of unexpected emergencies (Drèze and Modigliani, 1972). According to a classical theory regarding uncertain conditions known as the "preventive saving hypothesis," we can assume that the COVID-19 pandemic will increase the consumers' saving (vs. spending) behavior. This is because when consumers face uncertainty regarding the future, they make more precautionary savings (Kimball, 1990). At the same time, consumers expect the marginal utility of future consumption under uncertain circumstances to be greater than the marginal utility of future consumption under certain circumstances (Hau, 2002). Specifically, it can be expressed that the greater the uncertainty in the future, the greater the marginal utility of the consumers' expectation of future consumption. Therefore, they are more willing to increase precautionary savings to economically prepare for future consumption. Based on the above theory and logic analysis, the following hypothesis is proposed:

Hypothesis 1: The severity of the pandemic has a significant positive impact on the consumers' saving (vs. spending) behavior.

\section{Mediating Role of Risk Perception}

Previous studies on the consumers' saving and spending behavior (under uncertain environments) were mainly explained from an economic perspective without verifying the psychological mechanism underlying such behaviors. We will explore the consumers' internal psychological mechanisms behind behaviors based on a risk perception theory. Risk perception refers to the psychological reaction of the public when, during an emergency, they perceive a threat to life, property, and other valuables (Slovic, 1987; Setbon et al., 2005). According to the psychometric paradigm, an individual's risk perception is closely associated with the severity of the disaster event (Burns and Slovic, 2012). As seen in a typical public health emergency, the influences of COVID-19 pandemic are large and widespread, posing a serious threat to life and property and the physical and mental health of residents (Saddique et al., 2020). Because they are facing a severe pandemic control situation, the residents believe that the external environment is full of uncertainty and may have serious consequences. Therefore, under the influence of the pandemic, the residents' risk perception will increase. Further, the social amplification framework of risk indicates that the social nature of emergencies will also expand or strengthen the residents' risk perception (Kasperson et al., 1988). Based on the above theory and logic analysis, the following hypothesis is proposed:

Hypothesis 2: The severity of the pandemic has a significant positive impact on an individual's risk perception.

According to the risk perception theory, when individuals perceive external risks, they perform various actions to reduce the risks (Shi and Kim, 2020). Studies have found that individuals may adopt conservative ways to deal with risks (Sandmo, 1970). For example, individuals may reduce risks by strengthening resource reserves and by strategically allocating their resources 
(Durante and Laran, 2016). Therefore, under the influence of the risk perception influenced by the pandemic, consumers may increase their willingness to save and reduce their willingness to consume, thereby increasing their control over the uncertain environment and ensuring that they can use their currency resources in the future as and when required. In addition, the pandemic triggers an individual's perception of death risk. Studies have found that when someone around an individual died, they are more inclined to give up short-term benefits for long-term benefits, thereby saving more money than spending it (Brown and Walensky, 2020). Based on the above theory and logic analyses, the following hypothesis is proposed:

Hypothesis 3: Risk perception has a significant positive impact on an individual's saving (vs. spending) behavior.

The severity of the COVID-19 pandemic can increase environmental uncertainty and thus, stimulate an individual's risk perception. The more severe the pandemic, the stronger the individual's risk perception. When risk perception is stimulated, people are usually more eager to adopt a conservative economic strategy (Eeckhoudt and Schlesinger, 2008; Menegatti, 2015); therefore, they may prefer saving money rather than spending it. Corresponding to this, the following hypothesis is proposed:

Hypothesis 4: Risk perception plays a mediating role between the severity of the pandemic and an individual's saving (vs. spending) behavior.

\section{Does the Effect Continue During the Post-pandemic Period?}

Considering the effect of an individual's saving and spending behavior on economic recovery, studies on the effect of the severity of the COVID-19 pandemic on an individual's saving and spending behavior need to focus on the long-term effects, i.e., we need further studies to know if this effect still exists after the pandemic. By exploring an individual's psychology, we found that, in general, during a pandemic, consumers show an increase in their saving (vs. spending) behavior because they perceive risks. However, risk perception is a situational psychological variable (Slovic et al., 2004), when the situation changes, the individual's risk perception may change as well. According to the risk perception theory, the closer the disaster is, the higher the risk perception (Slovic, 2000). Thus, as the pandemic eases, the individual's risk perception is eliminated, and its impact on consumer saving and spending behavior also disappears. Therefore, the impact of the severity of a pandemic on consumers' saving and spending behavior is short-term and only exists during the pandemic. Based on the above theory and logic analysis, the following hypothesis is proposed:

Hypothesis 5: After the pandemic eases, the effects of a pandemic on an individual's saving (vs. spending) behavior will disappear.

\section{Moderating Role of Materialism}

Although we have proved that the COVID-19 pandemic will increase an individual's perception of risk and boost their saving (vs. spending) behavior, in reality, there are still many people who deal with anxiety; these individuals ease their anxiety (caused by the pandemic) through consumption. Existing literature supports that fact the people respond to a pandemic by increasing their consumption. For example, Hill et al. (1997) believed that in the face of a death threat, individuals perceive the finiteness of life, thereby increasing consumption and reducing savings. Therefore, the following question arises: during a pandemic, who are more inclined to save and who are more inclined to consume? We find that materialism may be an important factor. Materialism refers to a value orientation of an individual, which expresses the extent to which the individual takes the acquisition of material ownership as an indication of achieved life goals. Materialistic individuals achieve success and happiness by pursuing material wealth and focus their entire lives on the pursuit and acquisition of property (Belk, 1985; Richins and Dawson, 1992; Chan and Prendergast, 2007). When individuals perceive the risk of the pandemic, individuals with high materialism always seek to own more things than others, as they believe goods can bring happiness. Therefore, they place more value on goods, and are more eager to acquire and retain properties (Ger and Belk, 1996). Compared to individuals who have a low materialistic approach, materialist individuals are more likely to obtain psychological comfort through the consumption of materials so as to relieve anxiety. This results in an increase in their spending behavior. In addition, materialism is not only an individual characteristic but also a cultural value generally accepted by society (Bauman, 1995; Kasser and Ryan, 1996). By supporting cultural values, materialist individuals can alleviate their mental insecurity in a risky environment (Pyszczynski et al., 1997), and therefore, their money-saving behavior will decrease. Based on the above theory and logic analysis, the following hypothesis is proposed:

Hypothesis 6: Materialism plays a moderating role between risk perception and an individual's saving (vs. spending) behavior. That is, compared with individuals with low materialism, individuals with high materialism show a decreased saving (vs. spending) behavior when they perceive the risk of a pandemic.

\section{METHODS}

\section{Participants and Procedures}

We conducted two online questionnaire surveys on a professional platform named Credamo during and after the pandemic, which can provide large-scale data collection services and has been recognized by international top journals. The first survey was conducted during the COVID-19 outbreak (from February 10, 2020 to February 15, 2020). Credamo randomly distributed questionnaires in 31 provinces of China (excluding Hong Kong, Macao, and Taiwan) according to a quota of 50 copies in each province. A total of 1511 valid questionnaires were collected (with a recovery rate of 97.5\%), covering 297 prefecture-level cities in 31 provincial-level administrative regions in China, which can accurately and comprehensively describe the psychology and behavior of Chinese citizens during the COVID-19 pandemic. The sample included 678 female participants (44.9\%) and 833 male participants (55.1\%), aged $18-79$, and had a large share in income is below $3000 \mathrm{RMB}$ per month $(37.5 \%)$ and a significantly higher level education $(67.5 \%$ 
of participants had completed a college or university program). To verify the duration of the effect, we conducted a follow-up survey after the pandemic eased. As the COVID-19 pandemic had eased in China as of August 2020, with almost no new cases, we randomly distributed a total of 500 follow-up questionnaires from August 3, 2020 to August 6, 2020 among participants who participated in the first survey and didn't change location, entered their information in the database, and recovered 466 questionnaires (with a recovery rate of 93.2\%).

The questionnaire has passed the audit of Credamo, which guaranteed that it would not cause negative psychological effects on participants. As for the consent of participation, only those who agreed and volunteered to participate in surveys will access the questionnaire and corresponding remuneration. At the beginning of the questionnaire, we once again emphasized that "the survey results are only used for academic research, and the personal privacy of participants will be protected. If you agree and are participating voluntarily, start answering questions; if you disagree or are unsure, please exit." Each participant received $10 \mathrm{RMB}$. This research was approved by the ethics committee of Jilin University. The ethics committee reviewed the study proposal and consent of the participants. Besides, to ensure the validity of the questionnaire, we set up test items to assess if participants completed the answers carefully. Questionnaires that failed this test were not included in our database. The linear interpolation method was applied to provide missing values. A CHERRIES-compliant reporting checklist is in Additional file.

The demographic information of the sample is shown in Table 1.

\section{Measure}

Severity of pandemic (SE). As the severity of pandemic varied in different Chinese cities, we considered using official pandemic indicators of different regions issued by the National Health Commission of the People's Republic of China. Specifically, in the first survey, we recorded the date on which the participants completed the questionnaire along with the names of the cities they lived in. Then, we searched the official pandemic indicators for the same timeframe and place and included them in the database to match the corresponding psychological and behavioral data. We chose four representative indicators: the cumulative number of confirmed cases per province (CNP), the number of new confirmed cases per province (NNP), the cumulative number of confirmed cases per city $(\mathrm{CNC})$, and the number of new confirmed cases per city (NNC) to measure the SE and used them for hypothesis testing.

Saving and spending willingness (SA) was measured using a 7point Likert scale, and we designed a three-item scale to measure the construct according to Durante and Laran (2016)'s study. The content of this scale was that "to what extent are you willing to use your money for savings (and not spending) at the moment," "to what extent do you want to reduce spending money and increase savings in the future?" and "which one do you think is more important, saving or spending?"

Risk perception (RP) measurements were adapted from Katz et al. (2011), we aligned the measurements with a pandemic situation. The content of this scale was based on the following questions: "what do you think is the risk of COVID-19?" "how much do you think the COVID-19 pandemic poses a threat to health?" and "to what extent do you think COVID-19 has affected you?" All items used a 7-point Likert scale.

Materialism (MA) was measured based on Richins and Dawson (1992)'s study, which consists of 8 items. All items used a 5-point Likert scale ranging from 1 (very inconsistent) to 5 (very consistent).

Control variables. We also recorded the gender, age, education, and monthly income of the participants. As these variables may affect residents' saving and spending willingness, they were used as control variables.

\section{RESULTS}

\section{Reliability, Validity, and Measurement Model}

We conducted a confirmatory factor and reliability analyses to test the reliability of the measurement model. The results are shown in Table 2. All the values of the constructs' Cronbach's $\alpha$ exceeded 0.700. Except for materialism [AVE (average variance extracted $)=0.462$, nearly 0.500 ], the AVE of all other constructs exceeded 0.600 , exhibiting sufficient reliability and convergent validity. We also tested the measurement model through confirmatory factor analysis. Considering the large sample size in this study, which might cause a chi-square expansion, we used the Bollen-Stine bootstrapping technique (5,000 bootstrapping samples) for correction (Bollen and Stine, 1992). The results showed that the model fitting indexes of the measurement model met the minimum requirements of $\chi 2 / \mathrm{df}=1.092$, comparative fit index $[(\mathrm{CFI})=0.999]$, and root mean square error of approximation [RMSEA $=0.008$ ] (See Table 2).

We used a diagonal matrix analysis method to test the discrimination validity of the variables. The intercorrelations of the variables and their AVE square roots are reported in Table 3. The off-diagonal numbers are the correlations. The AVE square roots are given in bold on the diagonal values. If the correlation coefficients between the variables are smaller than their AVE square root, it proves that the discrimination validity of variables is desirable. As shown in Table 3, the discrimination validity of the variables is good.

\section{Hypothesis Tests \\ Analysis of Main Effect}

We established a regression to verify whether the main effect is established and whether it is situational. The results showed that the SE had a significant positive impact on the SA during the pandemic ( $\beta=0.051, p<0.05$ ) (see Table 4 for details); thus, the results verified H1. However, when the pandemic had eased, the SE had no significant influence on the SA $(\beta=0.008, p=$ 0.792) (see Table 6 for details), indicating that the SE positively affected the SA only during the pandemic. Thus, H5 was verified.

\section{Analysis of Mediating Effect}

We applied the regression analysis method proposed by Baron and Kenny (1986) to test the mediating role of RP between the $\mathrm{SE}$ and the SA during the pandemic. The results are shown in 
TABLE 1 | Demographic information of sample $(N=1511)$.

\begin{tabular}{|c|c|c|c|c|c|c|c|}
\hline Items & Options & Sample & Percentage (\%) & Items & Options & Sample & Percentage (\%) \\
\hline \multirow[t]{2}{*}{ Gender } & Male & 833 & 55.1 & Age & $<25$ & 704 & 46.6 \\
\hline & Female & 678 & 44.9 & & $25-40$ & 706 & 46.7 \\
\hline \multirow[t]{4}{*}{ Income per month } & $<3000 \mathrm{RMB}$ & 566 & 37.5 & & $>40$ & 101 & 6.7 \\
\hline & 3000-6000 & 543 & 35.9 & Education & High school & 351 & 23.2 \\
\hline & 6000-9000 & 245 & 16.2 & & Bachelor's degree & 1020 & 67.5 \\
\hline & >9000 RMB & 157 & 10.4 & & Master's degree & 140 & 9.3 \\
\hline
\end{tabular}

TABLE 2 | Reliability and validity analysis $(N=1511)$.

\begin{tabular}{|c|c|c|c|c|c|}
\hline $\begin{array}{l}\text { Variable } \\
\text { name }\end{array}$ & Item & $\begin{array}{l}\text { Standardized } \\
\text { factor loading }\end{array}$ & C.R. & AVE & Cronbach's $\alpha$ \\
\hline \multirow[t]{4}{*}{ SE } & CNP & 0.931 & 0.889 & 0.674 & 0.895 \\
\hline & NNP & 0.964 & & & \\
\hline & $\mathrm{CNC}$ & 0.659 & & & \\
\hline & NNC & 0.681 & & & \\
\hline \multirow[t]{3}{*}{ SA } & $\mathrm{SA} 1$ & 0.766 & 0.818 & 0.602 & 0.805 \\
\hline & $\mathrm{SA} 2$ & 0.693 & & & \\
\hline & SA3 & 0.860 & & & \\
\hline \multirow[t]{3}{*}{$\mathrm{RP}$} & $\mathrm{RP} 1$ & 0.815 & 0.838 & 0.633 & 0.836 \\
\hline & RP2 & 0.842 & & & \\
\hline & RP3 & 0.726 & & & \\
\hline \multirow[t]{8}{*}{ MA } & MA1 & 0.731 & 0.872 & 0.462 & 0.871 \\
\hline & MA2 & 0.680 & & & \\
\hline & MA3 & 0.697 & & & \\
\hline & MA4 & 0.645 & & & \\
\hline & MA5 & 0.702 & & & \\
\hline & MA6 & 0.776 & & & \\
\hline & MA7 & 0.605 & & & \\
\hline & MA8 & 0.578 & & & \\
\hline
\end{tabular}

C.R., composite reliability; AVE, average variance extracted; RMSEA, root mean square error of approximation; CFI, comparative fit index; IFI, incremental fit index; and TLI, Tucker-Lewis Index.

Table 4. The SE had a significant positive impact on the RP ( $\beta$ $=0.053, p<0.05)$ and the RP had a significant positive impact on the SA $(\beta=0.070, p<0.01)$. $\mathrm{H} 2$ and $\mathrm{H} 3$ were verified. After the addition of RP, the SE had no significant impact on the SA ( $\beta$ $=0.047, p>0.05$ ), indicating that RP played a fully mediating role between the SE and the SA during the pandemic. Thus, H4 was verified.

We used a bootstrap procedure to re-verify the mediating effect during the pandemic (Preacher et al., 2007). This procedure computed a $95 \%$ confidence interval (CI) for the indirect and direct effects through 5,000 sampling. If a CI does not include 0 , it indicates that the effect is significant. The results are shown in Table 5. The CI of the total effect [ $\beta=0.082,95 \%$ CI: $(0.001$, $0.163)]$ and the indirect effect $[\beta=0.006,95 \% \mathrm{CI}:(0.001,0.016)]$ did not include 0 , while the CI of the direct effect $[\beta=0.076$, $95 \%$ CI: $(-0.006,0.157)]$ included 0 , indicating that RP played a
TABLE 3 | Correlation and coefficient matrix $(N=1511)$.

\begin{tabular}{lcccc}
\hline & SE & RP & MA & SA \\
\hline SE & $\mathbf{0 . 8 2 1}$ & & & \\
RP & 0.036 & $\mathbf{0 . 7 9 6}$ & & \\
MA & $0.147^{\star \star}$ & 0.008 & $\mathbf{0 . 6 8 0}$ & \\
SA & 0.036 & $0.082^{\star \star}$ & -0.006 & $\mathbf{0 . 7 7 6}$ \\
\hline
\end{tabular}

${ }^{\star \star} p<0.01$. The diagonal bold numbers are AVE square roots.

significant mediating role between the SE and the SA during the pandemic. Thus, $\mathrm{H} 4$ was verified.

We used the same method to test the mediating role of RP between the SE and the SA during the post-pandemic period. The results are shown in Table 6. We observed that the SE had no significant positive impact on $\mathrm{RP}(\beta=0.013, p>0.05)$. The $\mathrm{RP}$ still had a significant positive impact on the SA $(\beta=0.124$, $p<0.01$ ), indicating that after the pandemic eases, the effect of SE on SA would disappear; this is because an individual's risk perception ceases to exist after the pandemic. Thus, $\mathrm{H} 5$ was verified again.

\section{Analysis of Moderating Effect}

This study uses hierarchical regression to analyze moderating effects. If the interaction item is significant, it means that the moderating effect is supported. Before the final calculation, all data were centralized to reduce the possible multicollinearity of the data. In the relationship between the SE and the RP, the M3 result showed that the value of RP $\times$ MA was -0.062 , the $T$ value was $-2.432, p<0.05\left(R^{2}=0.035\right.$, Adjust $R^{2}=0.031$, $\Delta R^{2}=0.004$, F-change $\left.=5.914\right)$, indicating that MA plays a significant negative moderating role between RP and SA. Thus, H6 was verified (see Table 7 ).

In order to further test the results of the regression analysis, we used a bootstrap method (sampling times of 5,000, 95\% confidence interval, model 14) for analysis. Only when the value of materialism was equal to the average $[\beta=0.006,95 \%$ CI: $(0.001,0.017)]$ and one standard deviation was lower than average $[\beta=0.011,95 \% \mathrm{CI}:(0.002,0.028)]$ was the indirect role of the SE on the SA significant. Thus, H6 is verified (see Table 8).

\section{GENERAL DISCUSSION}

This study explored the impact of the severity of the COVID-19 pandemic on an individual's saving and spending behavior and 
TABLE 4 | Regression test of the mediating effect during pandemic $(N=1511)$.

\begin{tabular}{|c|c|c|c|c|c|}
\hline \multirow[t]{2}{*}{ Variable } & \multicolumn{3}{|c|}{ SA } & \multicolumn{2}{|c|}{$\mathbf{R P}$} \\
\hline & Model 1 & Model 2 & Model 3 & Model 4 & Model 5 \\
\hline Gender (female $=0$ ) & $-0.060^{\star}$ & $-0.063^{\star}$ & $-0.065^{\star}$ & 0.028 & 0.025 \\
\hline Age & $0.109^{\star \star \star}$ & $0.106^{\star \star \star}$ & $0.104^{\star \star \star}$ & 0.040 & 0.037 \\
\hline Education & $0.074^{\star \star}$ & $0.074^{\star \star}$ & $0.072^{\star \star}$ & 0.038 & 0.039 \\
\hline Monthly income & $-0.111^{\star \star \star}$ & $-0.119^{\star \star \star}$ & $-0.110^{\star \star \star}$ & $-0.115^{\star \star \star}$ & $-0.124^{\star \star \star}$ \\
\hline SE & & $0.051^{*}$ & 0.047 & & $0.053^{*}$ \\
\hline $\mathrm{RP}$ & & & $0.070^{\star \star}$ & & \\
\hline$R^{2}$ & 0.026 & 0.029 & 0.034 & 0.011 & 0.014 \\
\hline $\operatorname{Adj} . R^{2}$ & 0.024 & 0.026 & 0.030 & 0.008 & 0.010 \\
\hline$F$ & $10.187^{\star \star \star}$ & $8.936^{\star \star \star}$ & $8.733^{\star \star \star}$ & $4.198^{\star \star}$ & $4.178^{\star \star \star}$ \\
\hline
\end{tabular}

TABLE 5 | Results of mediating effect during pandemic $(N=1511)$.

\begin{tabular}{|c|c|c|c|c|c|}
\hline \multirow[t]{2}{*}{ Path } & \multirow[t]{2}{*}{ Effect } & \multirow{2}{*}{$\begin{array}{c}\text { Standardized } \\
\text { estimate }\end{array}$} & \multirow{2}{*}{ S.E. } & \multicolumn{2}{|c|}{$95 \%$ Confidence intervals } \\
\hline & & & & LICl & ULCI \\
\hline SE->SA & Total effect & 0.082 & 0.042 & 0.001 & 0.163 \\
\hline SE->RP->SA & Indirect effect & 0.006 & 0.004 & 0.001 & 0.016 \\
\hline & Direct effect & 0.076 & 0.042 & -0.006 & 0.157 \\
\hline
\end{tabular}

its psychological mechanism. The results of the questionnaire survey are as follows: (1) the severity of pandemic is positively associated with an individual's saving (vs. spending) behavior; (2) the perceived risk plays a fully mediating role in the impact of the severity of pandemic on the saving and spending behavior i.e., the more severe the pandemic, the greater the risk perception of individuals and the higher their willingness to save (vs. spend); (3) after the pandemic eases, the effect of pandemic severity on individual's saving (vs. spending) behavior will disappear; (4) materialism plays a moderating role between the risk perception and the individual's saving and spending behavior. Compared to individuals with low materialism, individuals with high materialism have a lower saving (vs. spending) willingness when they perceive the risks of a pandemic. Therefore, this study provides sufficient empirical support for the relationship between the pandemic and the consumers' saving and spending behavior.

\section{Theoretical Contribution}

By exploring the relationship between the pandemic and an individual's saving and spending behavior, this research provides references for the study of emergencies and emergency management. An important innovation of research is the simultaneous analysis of the short-term and long-term effects of a pandemic on an individual's saving and spending behavior. Previous studies on the impact of emergencies mostly used secondhand data to verify this fact, which could not directly reflect the current psychology and psychological changes of residents; thus, previous studies could not verify the continuity in peoples' behaviors during emergencies. Through investigations
TABLE 6 | Regression test of mediating effect after pandemic $(N=466)$.

\begin{tabular}{|c|c|c|c|c|c|}
\hline \multirow[t]{2}{*}{ Variable } & \multicolumn{3}{|c|}{ SA } & \multicolumn{2}{|c|}{$\mathbf{R P}$} \\
\hline & Model 1 & Model 2 & Model 3 & Model 4 & Model 5 \\
\hline Gender (female = 0) & -0.089 & -0.089 & -0.088 & -0.008 & -0.009 \\
\hline Age & $-0.131^{\star \star}$ & $-0.130^{\star \star}$ & $-0.136^{\star \star}$ & 0.047 & 0.048 \\
\hline Education & -0.052 & -0.052 & -0.051 & -0.007 & -0.007 \\
\hline Monthly income & -0.052 & -0.055 & -0.056 & 0.009 & 0.004 \\
\hline SE & & 0.013 & 0.010 & & 0.022 \\
\hline $\mathrm{RP}$ & & & $0.124^{\star \star}$ & & \\
\hline$R^{2}$ & 0.034 & 0.034 & 0.049 & 0.003 & 0.003 \\
\hline $\operatorname{Adj} . R^{2}$ & 0.026 & 0.024 & 0.037 & -0.006 & -0.008 \\
\hline$F$ & $4.052^{\star \star}$ & $3.250^{\star \star}$ & $3.974^{\star \star \star}$ & 0.293 & 0.274 \\
\hline
\end{tabular}

${ }^{*} p<0.05,{ }^{* *} p<0.01$, and ${ }^{* * *} p<0.001$.

TABLE 7 | Regression test of moderating effect during pandemic $(N=1511)$.

\begin{tabular}{|c|c|c|c|c|c|c|}
\hline \multirow[t]{3}{*}{ Variable name } & \multicolumn{6}{|c|}{ SA } \\
\hline & \multicolumn{2}{|c|}{ M1 } & \multicolumn{2}{|c|}{ M2 } & \multicolumn{2}{|c|}{ M3 } \\
\hline & $\beta$ & $\mathbf{T}$ & $\beta$ & $\mathbf{T}$ & $\beta$ & $\mathbf{T}$ \\
\hline Sex & $-0.060^{\star}$ & -2.284 & $-0.062^{\star}$ & -2.366 & $-0.060^{\star}$ & -2.283 \\
\hline Age & $0.109^{\star \star \star}$ & 3.999 & $0.106^{\star \star \star}$ & 3.873 & $0.104^{\star \star \star}$ & 3.800 \\
\hline Monthly income & $-0.111^{\star \star \star}$ & -3.931 & $-0.102^{\star \star \star}$ & -3.619 & $-0.101^{\text {** }}$ & -3.567 \\
\hline Education & $0.074^{\star \star}$ & 2.808 & $0.071^{\star \star}$ & 2.708 & $0.070^{\star \star}$ & 2.666 \\
\hline $\mathrm{RP}$ & & & $0.072^{\star \star}$ & 2.839 & $0.074^{\star \star}$ & 2.886 \\
\hline MA & & & -0.002 & -0.085 & -0.003 & -0.126 \\
\hline $\mathrm{RP} \times \mathrm{MA}$ & & & & & $-0.062^{*}$ & -2.432 \\
\hline$R^{2}$ & \multicolumn{2}{|c|}{0.026} & \multicolumn{2}{|c|}{0.032} & \multicolumn{2}{|c|}{0.035} \\
\hline Adjust $R^{2}$ & \multicolumn{2}{|c|}{0.024} & \multicolumn{2}{|c|}{0.028} & \multicolumn{2}{|c|}{0.031} \\
\hline$F$ & \multicolumn{2}{|c|}{$10.187^{\star \star \star}$} & \multicolumn{2}{|c|}{$4.032^{\star}$} & \multicolumn{2}{|c|}{$5.914^{\star}$} \\
\hline
\end{tabular}

${ }^{\star} p<0.05,{ }^{\star \star} p<0.01$, and ${ }^{\star \star \star} p<0.001$.

TABLE 8 | Result of moderating effect during pandemic $(N=1511)$.

\begin{tabular}{lccccc}
\hline $\begin{array}{l}\text { Moderating } \\
\text { construct }\end{array}$ & Path & Value & Effect & \multicolumn{2}{c}{$\mathbf{9 5 \%}$ Confidence intervals } \\
\cline { 4 - 6 } & & & & LICI & ULCI \\
\hline MA & SE->RP->SA & 2.304 & 0.011 & 0.002 & 0.028 \\
& 3.045 & 0.006 & 0.001 & 0.017 \\
& 3.786 & 0.001 & -0.005 & 0.011
\end{tabular}

during and after the pandemic, we verified the sustainability of the effects of the pandemic on an individual's saving and spending behavior, which not only enriches and completes the relevant theories but also provides methodological references for related research.

Our study also made theoretical contributions to research in the fields of economics, psychology, and public health. First, the existing research on saving and spending under uncertain conditions only remains at the level of economic theory and fails to penetrate the consumers' psychology. We 
place saving and spending behavior in the context of a public health emergency and explain the mechanism between the pandemic and the consumers' saving and spending behavior from the dual perspectives of external environment and internal psychology. This helps us to deepen the exploration of relevant economic theory.

In the field of consumer psychology and behavior, research on saving and spending has gradually become a hot topic. However, related research is still in the initial stage and needs further exploration. We explored the impact of the pandemic on the saving and spending behavior of consumers' and found that risk perception plays a mediating role in this behavior. Additionally, materialism plays a moderating role in determining the behavior, which can be seen as a supplement to related content. At the same time, although materialism has become a universal cultural value, the term materialism still has a derogatory meaning, and research is mostly based on its negative influences. We discover the positive side of materialism i.e., materialism can provide individuals with psychological support in an unsafe and risky environment. The conclusion provides empirical support for the consumer behavior during emergencies and for the development of related theories about risk perception and materialism.

In the field of public health, previous studies of public health have focused primarily on infection prediction and health behaviors, however in public health emergencies, panic behavior need more attention. Recent studies have found that the pandemic cause more panic buying, for example, individuals may increase their purchases of necessities. Our study suggests that the savings behavior under COVID-19 pandemic can be regarded as a panic response behavior of individuals for future risks, which provides a new perspective for public health research. Also, most of the risk perception of emergencies has been verified under catastrophic emergencies. Our results once again verify the application of risk perception theory in public health emergencies, which can help grasp the public's psychology during the pandemic and contribute to build a reliable research framework for risk perception theory.

\section{Practical Implications}

Based on the COVID-19 pandemic, we analyze the impact of public health emergencies on an individual's saving and spending behavior in China through theoretical and empirical analysis. These research results have an important reference significance for the government's crisis response and emergency management. On the one hand, the findings verified that the materialism can moderate the approach which people cope with public health emergency, thereby promote individuals' normal consumption behavior, alleviate their panic behavior. On the other hand, we found that consumers, during the pandemic, are more inclined to save rather than consume. Although the effect is not long-term, from a socioeconomic perspective, this approach is not conducive to the recovery and development of the economic market. Therefore, the government can also take corresponding measures to promote their resident's consumption. Chinese government have taken corresponding measures to subsidize people's lives and stimulate consumption, such as issuing consumption coupons. This study found that individuals' risk perception of the pandemic is the key factor to affect their propensity to save and consume. Therefore, the government can popularize scientific knowledge of the pandemic to enhance people's understanding of the circumstance to comfort the residents, reduce their risk perception, and promote consumption. In general, the Chinese government should build confidence, firmly believe that the impact of the pandemic is short-term, strive to restore normal economic and social order, and promote stable and healthy economic development.

\section{Research Limitations and Future Research Directions}

This study has some limitations. First, we conducted research in China, which may be affected by social-cultural factors and show certain particularities. In the future, research can focus on the comparison of different countries with different social cultures. Second, this study selected the subjects randomly. In fact, the key individual of the family, who have more power to decide on saving money or spend it, need to be considered. Future study can pay attention to this and conduct in-depth research.

\section{DATA AVAILABILITY STATEMENT}

The original contributions presented in the study are included in the article/Supplementary Material, further inquiries can be directed to the corresponding author.

\section{ETHICS STATEMENT}

The studies involving human participants were reviewed and approved by Ethics committee of Jilin University. The patients/participants provided their written informed consent to participate in this study.

\section{AUTHOR CONTRIBUTIONS}

$\mathrm{XJ}$ and $\mathrm{YZ}$ devised the project, the main conceptual ideas, and proof outline. XJ and TZ collected the research data and revised the manuscript. YZ and WS analyzed the sequencing data and wrote the initial manuscript. All authors contributed to the article and approved the submitted version.

\section{FUNDING}

This research was funded by the National Natural Science Foundation of China (NSFC) (No. 71872070); Youth Program National Science Foundation of China (No. 71902069); Social Science Foundation of Jilin Province (No. 2020C060); Social Science Foundation of Jilin Province (No. 2019C31).

\section{SUPPLEMENTARY MATERIAL}

The Supplementary Material for this article can be found online at: https://www.frontiersin.org/articles/10.3389/fpsyg. 2021.636859/full\#supplementary-material 


\section{REFERENCES}

Arafat, S. M. Y., Kar, S. K., Marthoenis, M., Sharma, P., Apu, E. H., and Kabir, R. (2020a). Psychological underpinning of panic buying during pandemic (COVID-19). Psychiatry Res. 289:113061. doi: 10.1016/j.psychres.2020.113061

Arafat, S. M. Y., Kar, S. K., Menon, V., Kaliamoorthy, C., Mukherjee, S., AlradieMohamed, A., et al. (2020b). Panic buying: an insight from the content analysis of media reports during COVID-19 pandemic. Neurol. Psychiatry Brain Res. 37, 100-103. doi: 10.1016/j.npbr.2020.07.002

Baron, R. M., and Kenny, D. A. (1986). The moderator-mediator variable distinction in social psychological research: conceptual, strategic, and statistical considerations. J. Pers. Soc. Psychol. 51, 1173-1182. doi: 10.1037/0022-3514.51.6.1173

Bauman, Z. (1995). Life in Fragments: Essays in Postmodern Morality. London: Blackwell.

Behar-Zusman, V., Chavez, J. V., and Gattamorta, K. (2020). Developing a measure of the impact of COVID-19 social distancing on household conflict and cohesion. Fam. Process 59, 1045-1059. doi: 10.1111/famp.12579

Belk, R. W. (1985). Materialism: trait aspects of living in the material word. J. Consum. Res. 12, 265-279. doi: 10.1086/208515

Bollen, K. A., and Stine, R. A. (1992). Bootstrapping goodness-of-fit measures in structural equation models. Sociol. Methods Res. 21, 205-229. doi: $10.1177 / 0049124192021002004$

Brown, T. S., and Walensky, R. P. (2020). Serosurveillance and the COVID-19 epidemic in the US: undetected, uncertain, and out of control. J. Am. Med. Assoc. 324, 749-751. doi: 10.1001/jama.2020.14017

Bureau of Economic Analysis (2020). Available online at: http://www.bea.gov/ (accessed May 29, 2020).

Burns, W. J., and Slovic, P. (2012). Risk perception and behaviors: anticipating and responding to crises. Risk Anal. 32, 579-582. doi: $10.1111 / j .1539-6924.2012 .01791 . x$

Cable News Network (2020). Available online at: https://zh.apdnews.com/world/ 989770.html (accessed May 12, 2020).

Chan, K., and Prendergast, G. (2007). Materialism and social comparison among adolescents. Soc. Behav. Pers. Int. J. 35, 213-228. doi: 10.2224/sbp.2007.35.2.213

Choi, G., Kim, I., and Snow, A. (2001). Comparative statics predictions for changes in uncertainty in the portfolio and savings problems. Bull. Econ. Res. 53, 61-72. doi: 10.1111/1467-8586.00118

De Rugy, V. (2004). Why don't Americans save their money? Reason 46, 18-19. Available online at: http://search.ebscohost.com/login.aspx?direct=true\&db= a9h\&AN=99211726\&lang $=\mathrm{zh}-\mathrm{cn} \&$ site $=$ ehost-live

Drèze, J., and Modigliani, F. (1972). Consumption decision under uncertainty. J. Econ. Theory 5, 308-335. doi: 10.1016/0022-0531(72)90044-0

Durante, K. M., and Laran, J. (2016). The effect of stress on consumer saving and spending. J. Mark. Res. 53, 814-828. doi: 10.1509/jmr.15.0319

Eeckhoudt, L., and Schlesinger, H. (2008). Changes in risk and the demand for savings. J. Monet. Econ. 55, 1329-1336. doi: 10.1016/j.jmoneco.2008.08.004

Fidelity International and Alipay (2020). Survey Report on China's Pension Prospects in the Post-Epidemic Era. Available online at: http://www.fidelity. com.cn/zh-cn/market-insights/china-retirement-readiness-survey-2020-fullreport/ (accessed September 17, 2020).

Ger, G., and Belk, R. W. (1996). Cross cultural differences in materialism. J. Econ. Psychol. 17, 55-77. doi: 10.1016/0167-4870(95)00035-6

Hau, A. (2002). Prudence, intertemporal substitution, and savings under uncertainty. J. Econ. 77, 35-52. doi: 10.1007/s007120200050

Hill, E. M., Ross, L. T., and Low, B. S. (1997). The role of future unpredictability in human risk-taking. Hum. Nat. 8, 287-325. doi: 10.1007/BF02913037

Jin, X., Li, J., Song, W., and Zhao, T. (2020). The impact of COVID-19 and public health emergencies on consumer purchase of scarce products in China. Front. Public Health 8:617166. doi: 10.3389/fpubh.2020.617166

Kasperson, R. E.;, Renn, O., Slovic, P., Brown, H. S., Emel, J., Goble, R., et al. (1988). The social amplification of risk: a conceptual framework. Risk Anal. 8, 177-187. doi: 10.1111/j.1539-6924.1988.tb01168.x

Kasser, T., and Ryan, R. M. (1996). Further examining the American dream: differential correlates of intrinsic and extrinsic goals. Pers. Soc. Psychol. Bull. 22, 280-287. doi: $10.1177 / 0146167296223006$

Katz, M. L., Krieger, J. L., and Roberto, A. J. (2011). Human papillomavirus (HPV): college male's knowledge, perceived risk, sources of information, vaccine barriers and communication. J. Mens Health 8, 175-184. doi: $10.1016 /$ j.jomh.2011.04.002

Kimball, M. S. (1990). Precautionary savings in the small and in the large. Econometrica 58, 53-73. doi: 10.2307/2938334

Leland, H. E. (1968). Saving and uncertainty: the precautionary demand for saving. Q. J. Econ. $82,465-473$. doi: $10.2307 / 1879518$

Menegatti, M. (2001). On the conditions for precautionary saving. J. Econ. Theory 98, 189-193. doi: 10.1006/jeth.2000.2751

Menegatti, M. (2015). New results on high-order risk changes. Eur. J. Oper. Res. 243, 678-681. doi: 10.1016/j.ejor.2014.12.023

Modigliani, F., and Brumberg, R. (1954). "Utility analysis and the consumption function: an interpretation of cross-section data," in Post Keynesian Economics, ed K. Kurihara (New Brunswick, NJ: Rutgers University Press), 388-436.

Muthuraman, S., and Haziazi, M. A. (2020). COVID-19 Impact on health, social, and economy. Int. J. Nutr. Pharmacol. Neurol. Dis. 10, 159-160. doi: 10.4103/ijnpnd.ijnpnd_64_20

Preacher, K. J., Rucker, D. D., and Hayes, A. F. (2007). Addressing moderated mediation hypotheses: theory, methods, and prescriptions. Multivar. Behav. Res. 42, 185-227. doi: 10.1080/00273170701341316

Pyszczynski, T., Greenberg, J., and Solomon, S. (1997). Why do we need what we need? a terror management perspective on roots of human social motivation. Psychol. Inq. 8, 1-20. doi: 10.1207/s15327965pli0801_1

Richins, M. L., and Dawson, S. (1992). A consumer values orientation for materialism and its measurement: scale development and validation. J. Consum. Res. 19, 303-316. doi: 10.1086/209304

Saddique, A., Rana, M. S., Alam, M. M., et al. (2020). Emergence of co-infection of COVID-19 and dengue: a serious public health threat. J. Infect. 81, e16-e18. doi: 10.1016/j.jinf.2020.08.009

Sandmo, A. (1970). The effect of uncertainty on saving decisions. Rev. Econ. Stud. 37, 353-360. doi: 10.2307/2296725

Setbon, M., Raude, J., Fischler, C., and Flahault, A. (2005). Risk perception of the "mad cow disease" in France: determinants and consequences. Risk Anal. Int. J. 25, 813-826. doi: 10.1111/j.1539-6924.2005.00634.x

Sharma, P., Kar, S. K., Menon, V., Ravi, C.,Mukherjee, S., Alradie-Mohamed, A., et al. (2020). Panic buying: is it a normal social construct? Anatol. J. Fam. Med. 3, 270-271. doi: 10.5505/anatoljfm.2020.52523

Shi, J., and Kim, H. K. (2020). Integrating risk perception attitude framework and the theory of planned behavior to predict mental health promotion behaviors among young adults. Health Commun. 35, 597-606. doi: 10.1080/10410236.2019.1573298

Slovic, P. (1987). Perception of risk. Ence 236, 280-285. doi: 10.1126/science. 3563507

Slovic, P. (2000). The Perception of risk. Risk Soc. Policy. 69, 112-112. doi: $10.4324 / 9781315661773$

Slovic, P., Finucane, M. L., Peters, E., MacGregor, D. G. (2004). Risk as analysis and risk as feelings: some thoughts about affect, reason, risk, and rationality. Risk Anal. 24, 311-322. doi: 10.1111/j.0272-4332.2004.00433.x

Survey and Research Center for China Household Finance (2020). China Household Wealth Index Survey Report (Q1 2020). Available online at: https:// chfs.swufe.edu.cn/uploads/20200423/53dccb967a3a723b60d62e2363f6eaf6.pdf (accessed April 21, 2020).

Wang, Q., and Su, M. (2020). A preliminary assessment of the impact of COVID19 on environment-a case study of China. Sci Tot. Environ. 728:138915. doi: 10.1016/j.scitotenv.2020.138915

Yuen, K. F., Wang, X., Ma, F., and Li, K. X. (2020). The psychological causes of panic buying following a health crisis. Int. J. Environ. Res. Public Health 17:3513. doi: 10.3390/ijerph17103513

Conflict of Interest: The authors declare that the research was conducted in the absence of any commercial or financial relationships that could be construed as a potential conflict of interest.

Copyright ( 2021 Jin, Zhao, Song and Zhao. This is an open-access article distributed under the terms of the Creative Commons Attribution License (CC BY). The use, distribution or reproduction in other forums is permitted, provided the original author(s) and the copyright owner(s) are credited and that the original publication in this journal is cited, in accordance with accepted academic practice. No use, distribution or reproduction is permitted which does not comply with these terms. 